\title{
Compulsão, criminalidade, destruição e perdas: o significado do crack para os usuários
}

Recebido em: 26/04/2012 Aceito em: 27/09/2012
Fernanda Matos Fernandes Castelo Branco ${ }^{1}$ Maysa Nayra Pimentel de Sousa² Nellyda Carvalho Cruz Brito ${ }^{3}$ Vallone Luiz Paes de Oliveira Rocha ${ }^{4}$ Juliana Macêdo de Medeiros ${ }^{5}$ Fernando José Guedes da Silva Junior ${ }^{6}$ Claudete Ferreira de Souza Monteiro ${ }^{7}$

Objetivou-se analisar o significado do crack para usuários do Centro de Atenção Psicossocial para dependentes de Álcool e outras Drogas. Trata-se de um estudo de abordagem qualitativa, realizado no mês de março de 2012. Participaram nove sujeitos que responderam a um roteiro de entrevista semiestruturado. As falas dos depoentes foram submetidas a análise temática. Os relatos evidenciaram que o crack significa, para os usuários, destruição, compulsividade, criminalidade, agressividade e perdas afetivas, familiares e materiais. Percebe-se que compreender esses significados na concepção de seus usuários é o caminho necessário para um redirecionamento da assistência prestada pela equipe de saúde.

Palavras chave: Enfermagem, Cocaína, Crack, Saúde Mental.

\section{Compulsion, criminality, destruction and loss: the meaning of crack for its users}

This study aimed to analyze the meaning of crack for users at the Center for Psychosocial Care for dependents of Alcohol and other Drugs. This is a qualitative study, conducted in March 2012. Nine participants answered a semi-structured interview. The statements of the users were subjected to thematic analysis. The reports showed that, for its users, crack means destruction, compulsivity, criminality, aggressiveness and material, emotional and family losses. It is evident that understanding such meanings for the users is the necessary path to a redirection of care as provided by the healthcare team.

Descriptors: Nursing, Cocaine, Crack, Mental Health.

\section{Compulsión, criminalidad, destrucción y pérdida: la importancia del crack para sus usuarios}

Este estudio tuvo como objetivo analizar la importancia del crack para sus usuarios en el Centro de Atención Psicosocial para dependientes de Alcohol y Otras Drogas. Se trata de un estudio cualitativo, realizado en marzo de 2012. Participaron nueve individuos que respondieron a una entrevista semiestructurada. Las declaraciones de los usuarios fueron sometidas a análisis temático. Los informes muestran que el crack significa, para los usuarios, destrucción, compulsividad, criminalidad, agresividad y pérdidas emocionales, familiares y materiales. Se observa que entender estos significados para los usuarios es el camino necesario para una reorientación de la atención prestada por el equipo de salud.

Descriptores: Enfermería, Cocaína, Crack, Salud Mental.

\section{INTRODUÇÃO}

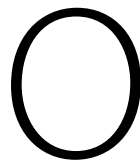
uso de substâncias psicoativas não se configura em uma prática nova no curso histórico da humanidade. Esse fenômeno esteve presente em diversas sociedades, sobretudo associado a tradições socioculturais, rituais místicos e religiosos e até mesmo utilizado como objeto de interação social considerando seu suposto caráter terapêutico.

Atualmente, o consumo de tais substâncias tem adquirido grandes proporções em detrimento à desvirtuação de sua finalidade inicial sendo, pois, responsável por gerar amplo debate no meio social, não somente pelos efeitos devastadores provocados nos usuários (ameaça à saúde, improdutividade laboral e ainda prejuízo na qualidade de vida), mas, principalmente, pela sua teia de destruição que contribui para o aumento da criminalidade e marginalidade ${ }^{(1)}$.

Ao chamar atenção para o fenômeno das drogas, subleva-se grande preocupação com o consumo do crack: potente estimulante do sistema nervoso central, que gera alto grau de dependência, além de ser bastante comum nos atos proibidos pela Lei. Essa substância atinge $0,3 \%$ da população mundial. No Brasil, estima-se que $0,7 \%$ da população já tenha consumido a droga, com destaque para as regiões Sul $(3,6 \%)$, Sudeste $(2,6 \%)$ e Nordeste $(1,4 \%)$, cujo perfil é de usuários jovens, estudantes do ensino médio e fundamental,

1 Enfermeira. Mestranda em Saúde da Família pelo Centro Universitário Novafapi (Uninovafapi). Docente da Uninovafapi. Email: fmfernandes@globo.com 2 Discente da Graduação em Enfermagem da Uninovafapi.

3 Discente da Graduação em Enfermagem da Uninovafapi.

4 Discente da Graduação em Enfermagem da Uninovafapi.

5 Enfermeira. Mestranda em Saúde da Família pelo Centro Universitário Novafapi (Uninovafapi). Docente da Uninovafapi.

6 Enfermeiro. Mestrando em Enfermagem pela Universidade Federal do Piauí.

7 Enfermeira. Doutora em Enfermagem. Docente da Universidade Federal do Piaui. Email: claudetefmonteiro@hotmail.com 
predominantemente de baixa renda ${ }^{(2-5)}$.

O consumo do crack incita um padrão intenso, contínuo e repetitivo, faz com que as consequências transgridam o usuário e se estenda a toda sua conjuntura familiar e social. A urgência pelo crack juntamente com a intensidade dos efeitos causados por sua busca, coloca essa droga como um grave problema de saúde pública, tendo em vista a violência e os comportamentos sexuais de risco que estão associados ao seu consumo e que atingem não só o usuário como a sociedade de forma geral, podendo disseminar doenças e acarretar danos à segurança da população(6).

Nesse contexto, a dependência química, com ênfase no crack, tem desafiado gestores, profissionais da saúde e a comunidade em geral, tendo em vista as dificuldades de manejo e abordagem dessa problemática, além da evidência de que os danos causados em consequência do uso dessas drogas atingem diversos segmentos da sociedade. Nesse sentido, faz-se imperativo o desenvolvimento de estudos congêneres no intuito de contribuir para a redução de danos decorrentes dessa vivência com o crack.

Destaca-se ainda que a relevância desta produção reside no fato de que parte das produções científicas sobre o crack possuem como objeto os profissionais de saúde ou as instituições que prestam atendimento a esses indivíduos, deixando de lado a abordagem da problemática sob a perspectiva dos próprios usuários.

Desta maneira, faz-se congruente a busca pelos significados atribuídos ao crack sob a ótica dos próprios usuários, uma vez que esta poderá nortear a atuação das equipes multidisciplinares, visando à prevenção do uso de drogas e quiçá seja o ponto de partida para o desenvolvimento de uma nova perspectiva terapêutica centrada no cliente. Assim, o estudo objetivou analisar o significado do crack para usuários do Centro de Atenção Psicossocial para Dependentes de Álcool e Outras Drogas (CAPSad).

\section{METODOLOGIA}

O estudo realizado é de abordagem qualitativa realizada em um CAPSad do estado do Maranhão. Os sujeitos do estudo foram nove usuários de crack, maiores de 18 anos, que tivessem consumido a droga por pelo menos um ano. Inicialmente buscou-se a identificação dos usuários por meio de seus respectivos prontuários.

A seguir, foram encaminhados para avaliação por membros da equipe, preferencialmente, psiquiatra, psicólogo ou enfermeiro para identificação dos sujeitos que estivessem em condição de fala, que não apresentassem comprometimento a ponto de prejudicar a realização da entrevista e que aceitassem, voluntariamente, participar do estudo com a assinatura do Termo de Consentimento Livre e Esclarecido. Os sujeitos foram identificados pela ordem da realização das entrevistas sendo utilizados a letra " $E$ " e o número correspondente.

A produção dos dados foi feita no mês de março de 2012 por meio de entrevista semiestruturada. $O$ instrumento foi elaborado pelos próprios pesquisadores e continha uma pergunta aberta: o que o crack significa para você? As entrevistas foram realizadas em salas reservadas para garantir o sigilo dos entrevistados, tendo uma duração média de 20 minutos cada uma, sendo captadas por meio de Mp4. Posteriormente foram transcritas na íntegra dando subsídio para a análise temática realizada. Vale destacar que as entrevistas só deixaram de ser realizadas quando os dados se tornaram repetitivos.

A pesquisa foi aprovada pelo Comitê de Ética e Pesquisa do Centro Universitário Novafapi (Uninovafapi), com parecer do Processo CAAE n 0373.0.043.000-11, juntamente com a autorização da Secretaria Municipal de Saúde, órgão este responsável e competente pela Instituição envolvida no estudo para a liberação da coleta de dados.

\section{RESULTADOS E DISCUSSÃO}

Os sujeitos pesquisados foram nove usuários de crack, de ambos os sexos, a maioria do sexo masculino, solteiros, católicos, na faixa etária compreendida entre 21 e 50 anos, com escolaridade variando entre ensino fundamental incompleto e ensino médio completo.

A leitura atentiva da fala dos sujeitos foi repetida várias vezes até que se tornasse evidente, tomando um sentido significativo. Só depois as categorias analíticas acerca dos significados do crack para os usuários foram organizadas. A partir desses relatos pode-se evidenciar que o crack significa destruição, perdas materiais, familiares e afetivas, compulsão, criminalidade e agressividade.

\section{O crack como instrumento de destruição, perdas familiares, afetivas e materiais}

O uso abusivo das drogas, em especial do crack, é indubitavelmente um fenômeno grave e complexo. Os sujeitos do estudo relatam que a busca pela droga é entendida como um caminho supostamente efetivo para superar as diversas dificuldades vivenciadas no cotidiano. Entretanto, ao se inserirem nesse contexto de dependência compreendem essa realidade como um caminho tortuoso, destrutivo e permeado por diversas perdas: familiares, afetivas e materiais.

"O significado não é bom, não, só mesmo destruição e atraso na vida da gente." (E2)

"Destruição. O crack só destruiu a minha vida. Perdi minha namorada, minha moral, perdi tudo [...] a minha vida tá desgraçada demais, não é vida de gente, é vida de cão e isso eu não quero pra ninguém." (E4) 
"Perdi casa, perdi marido, perdi praticamente o amor da minha família, que hoje, aos poucos, estou conquistando, mas antigamente com a droga eu não tinha o amor da minha família." (E5)

"Primeiro eu parei logo de estudar, aí vendi minha casa, tanta coisa, mas a mudança maior foi que vendi minha casa, as amizades também, que eu falava antes hoje nem falam mais, meus parentes também." (E6)

"Eu perdi minha família, eu perdi minha esposa, eu perdi meu trabalho, eu perdi tudo, joguei tudo pro ar e hoje eu não tenho nada." (E7)

Ao analisar os relatos desses usuários, destaca-se que suas histórias de vida, de forma geral, envolvem muitas perdas. Estas estão entrelaçadas nesse caminhar com a droga proporcionando um sofrimento singular vivenciado a partir de suas experiências com o crack.

A sensação de vazio, a solidão, a ausência de pessoas que compreendam a ação devastadora do crack na vida desse usuário o levam a um sofrimento incomparável e sublevam sua trajetória de vida trilhada até então pelos caminhos ilícitos, impedindo, pois, a possibilidade de reestruturação pessoal, familiar e ocupacional.

É possível visualizar os rompimentos dos relacionamentos afetivos como uma dimensão relevante que está associada à ação do crack. O findar-se de casamentos, uniões estáveis e namoros possui relação direta com a ação da droga na vida de seus usuários, uma vez que o poder protagonizador do crack impede que as pessoas e as relações afetivas, fraternais e familiares sejam positivas na vida daqueles que convivem com essa droga.

As perdas materiais e aquelas relacionadas ao trabalho também são destacadas nos depoimentos dos entrevistados. Essas repercussões sociais possuem um entremeio biológico significativo, que associa essas perdas ao forte poder de dependência que está imbricado no consumo do crack.

O uso do crack traz inúmeros problemas de ordem física, psiquiátrica, mas, sobretudo, social, notadamente percebida pelas alterações de humor, com ênfase na anedonia; dificuldade de manipular informações na mente; e déficits na tomada de decisões ${ }^{(7)}$. Essas dificuldades que emergem com o uso da droga contribuem para a perda do vínculo com o trabalho e a ausência dos valores atribuídos aos bens adquiridos ao longo da vida.

O crack é instrumento de todas essas consequências negativas na vida de seus usuários. A elas estão entrelaçadas as perdas que vão desde objetos pessoais até o afastamento da sociedade e o isolamento para o consumo incessante dessa droga ${ }^{(8)}$. Família, amigos e suas relações amorosas não suportam a nova rotina vivida a partir da inserção do crack em suas vidas. A ausência de um verdadeiro e significativo sentido existencial contribui para a deturpação do respeito, da confiança e da credibilidade que lhes eram atribuídos antes da dependência.

\section{Compulsão, agressividade e criminalidade: elementos presentes na dinâmica da depedência pelo crack}

O uso do crack incita um padrão de consumo intenso, contínuo e repetitivo. A necessidade de utilização de doses repetidas dessa droga transgride valores sociais, morais e constitucionais, subsidiando, muitas vezes, o emergir de manifestações agressivas, violentas, inquietas, principalmente quando não está em uso. Essa realidade foi destacada de forma pontual na vida dos entrevistados.

"O crack a pessoa fuma e tem vontade de fumar mais, dar vontade de roubar, até de matar dar pra poder usar o crack." (E1)

"É como um abismo num tem, uma coisa que você nunca vai se satisfazer num tem, quanto mais você tem, mais você quer [...] não tava comendo, não tava dormindo." (E2)

"Pra eu conseguir o crack, tinha que roubar." (E3)

"Estourei tudo com o crack [...] a roubar $e$, às vezes, dava vontade de até matar um, mas eu me segurava, pois o crack é perdição." (E5)

"Essa droga não satisfaz, entendeu? Enquanto você não passa mal ou morre você tá usando, você não come apenas bebe porque dá sede, você não come, não sente fome, enquanto tá usando, não come nada." (E4)

"Fui pegando coisas alheias, pois eu nunca roubei depois de usar o crack que eu comecei a roubar." (E8)

"Você fuma uma e dá vontade de fumar dez. E ninguém pode falar nada porque vem uma fúria, uma raiva, não sei explicar." (E9)

A urgência pelo crack e a falta de condições financeiras para suprir sua demanda colocam o usuário em situação de fragilidade, em que se submete a estratégias arriscadas para obtenção da droga, tais como situações de risco: tráfico de drogas e sexo sem proteção, por exemplo. Essa realidade de viver e conviver com droga subsidia, ainda, o envolvimento desse usuário com situações violentas, seja como ator ou vítima, repercutindo de maneira particular em suas vidas.

O crack é uma substância capaz de suscitar um desejo incontrolável de usar a droga repetidas vezes. Traz consigo ansiedade, mal-estar e uma ideia contínua de que essas sensações só pararão com o novo uso, o que incapacita a pessoa de sentir outros prazeres ou de ter outras vontades ${ }^{(9)}$. Essa imperativa necessidade de consumo do crack fomenta ainda, por vezes, o emergir de uma pessoa com comportamento agressivo e violento.

Estudo demonstra que essa característica encontra-se relacionada à ação dessa substância no todo orgânico do usuário e evidenciado pela paranoia, a qual é caracterizada 
por uma distorção da realidade, acompanhada por alucinações (alterações da sensopercepção) e delírios (alterações do conteúdo do pensamento), que quase sempre são de cunho persecutório, o que gera uma sensação contínua de ameaça(10).

Os relatos de maneira enfática trazem em seu bojo vivências de suas práticas ilícitas, as quais afirmam já terem praticado: a subtração de objetos como ação para a obtenção de dinheiro para a compra da droga. Pesquisa congênere destaca que roubos, assaltos, situações de violência e atos ilícitos são bastante comuns neste "mundo" e protagonizam na pluralidade das vezes o rompimento de relações e vínculos dos usuários com o meio em que vivem ${ }^{(11)}$.

É, pois, nesse trilhar percorrido pelos usuários de crack que se destaca que é inevitável não se associarem com crimes e violências. Sob efeito da droga, ou sobretudo na vivência da "fissura", são capazes de protagonizar atos inimagináveis, uma vez que preferem dedicar-se à realização de atividades ilícitas cujo retorno financeiro é rápido, embora firam a sua moral pessoal e familiar.

\section{CONCLUSÃO}

A busca pela subjetividade que permeia a vida dos usuários de crack evidenciada por meio dessa pesquisa qualitativa abre-se como uma concepção oportuna para o estudo de uma fenômeno contemporâneo e grave.

Os resultados evidenciam que os significados atribuídos ao crack pelos usuários estão entrelaçados ao seu poder devastador, destrutivo, agressivo, compulsivo e corresponsável por perdas afetivas, familiares e materiais.

Portanto, compreender esses significados na concepção de seus usuários, conhecendo as principais repercussões em suas vidas e de seus familiares, é o caminho necessário para um redirecionamento da assistência prestada pela equipe de saúde.

A complexidade com que esse fenômeno se apresenta torna imperativa a necessidade de compressão desse movimento de busca pelo crack, o que incita a importância de adoção estratégias de enfrentamento efetivas para que esses usuários possam entender que é possível o restabelecimento de sua vida e de sua saúde.

Como limitação do estudo, cita-se a amostra do tipo intencional. Assim, visualizaram-se os significados do crack atribuídos pelo grupo entrevistado. No entanto, os resultados não podem ser generalizados, tampouco utilizados para representar toda a população de usuários e ex-usuários de crack.

\section{Referências}

1. Oliveira LG, Nappo SA. Caracterização da cultura de crack na cidade de São

Paulo: padrão de uso controlado. Rev Saúde Pública. 2008;42(4):664-71.

2. Ribeiro M, Dunn J, Sesso R, Dias AC, Laranjeira R. Causes of death among crack

cocaine users. Rev Bras Psiquiatr. 2006;28(3):196-202.

3. Galduróz JC, Noto AR, Nappo AS, Carlini EA. Uso de drogas psicotrópicas no

Brasil: pesquisa domiciliar envolvendo as 107 maiores cidades do país - 2001. Rev Latinoam Enferm. 2005;13(Esp):888-95.

4. Duailibi LB, Ribeiro M, Laranjeira R. Profile of cocaine and crack users in Brazil. Cad Saúde Pública. 2008;24(4):545-57.

5. Bernardy CCF, Oliveira MLF. O papel das relações familiares na iniciação ao

uso de drogas de abuso por jovens institucionalizados. Rev Esc Enferm USP.

2010;44(1):11-7.

6. Chaves TV, Sanchez ZM, Ribeiro LA, Nappo SA. Fissura por crack:

comportamentos e estratégias de controle de usuários e ex-usuários. Rev Saúde
Pública. 2011;45(6):1168-75.

7. Cunha PJ, Nicastri S, Gomes LP, Moino RM, Peluso MA. Alterações

neuropsicológicas em dependentes de cocaína/crack internados: dados

preliminares. Rev Bras Psiquiatr. 2004;26(2):103-6.

8. Almeida RBF. O caminho das pedras: conhecendo melhor os usuários de

crack do município de Recife-PE [dissertação]. Recife: Universidade Católica de Pernambuco; 2010.

9. Raupp L, Adorno RCF. Circuitos de uso de crack na regiăo central da cidade de São Paulo (SP, Brasil). Ciênc Saúde Coletiva. 2009;16(5):29-37.

10. Ribeiro LA, Sanchez ZM, Nappo SA. Estratégias desenvolvidas por usuários de crack para lidar com os riscos decorrentes do consumo da droga. J Bras Psiquiatr. 2010;59(3):210.

11. Neves ACL, Miasso Al. "Uma força que atrai": o significado das drogas para usuários de uma ilha de Cabo Verde. Rev Latinoam Enferm. 2010;18(2):159-68. 